\title{
A Brief Overview of the Last 10 Years of Major Late Pleistocene Discoveries in the Old World: Homo floresiensis, Neanderthal, and Denisovan
}

\author{
Fernanda Neubauer \\ Department of Anthropology, University of Wisconsin-Madison, Madison, WI 53706, USA \\ Correspondence should be addressed to Fernanda Neubauer; fneubauer@wisc.edu
}

Received 26 February 2014; Revised 6 May 2014; Accepted 26 May 2014; Published 15 June 2014

Academic Editor: Santos Alonso

Copyright (c) 2014 Fernanda Neubauer. This is an open access article distributed under the Creative Commons Attribution License, which permits unrestricted use, distribution, and reproduction in any medium, provided the original work is properly cited.

\begin{abstract}
In the last ten years, new fossil, archaeological, and genetic data have significantly altered our understanding of the peopling of the Old World in the Late Pleistocene. Scholars have long been challenged to define humanity's place in evolution and to trace our phylogeny. Differences in the skeletal morphology of hominin fossils have often led to the naming of distinct new species, but recent genetic findings have challenged the traditional perspective by demonstrating that modern human DNA contains genes inherited from Neanderthals and Denisovans, thus questioning their status as separate species. The recent discovery of Homo floresiensis from Flores Island has also raised interesting queries about how much genetic and morphological diversity was present during the Late Pleistocene. This paper discusses the nature and implications of the evidence with respect to Homo floresiensis, Neanderthals, and Denisovans and briefly reviews major Late Pleistocene discoveries from the last ten years of research in the Old World and their significance to the study of human evolution.
\end{abstract}

\section{Introduction}

In the literature of human evolution, recent years have been marked by new questions of what it means to be human. Scholars have long been challenged to define humans' place in evolution and to trace our phylogeny. Differences in the skeletal morphology of hominin fossils have often led to the naming of distinct new species. Species are traditionally and most often defined as a population or group of populations capable of interbreeding and producing fertile offspring [1], although Mayden [2] more recently have identified at least 24 alternative species conceptualizations (see also de Queiroz [3] for a discussion of modern versus traditional species definitions).

Recent genetic findings have challenged the traditional biological perspective by demonstrating that modern human DNA contains genes inherited from Neanderthals and Denisovans [4-6]. Not only do modern humans partially share their lineage but genetic evidences also indicate that these different hominins were capable of interbreeding and producing viable offspring, thus questioning their status as separate species. Genetic data to date indicate that at least Neanderthals, anatomically modern humans (AMH, i.e., humans with skeletons similar to those of presentday humans), and Denisovans were variants of a single breeding population of Homo, even though they present vast spatiotemporal differences in their skeletal morphology and artifactual productions. Despite these findings, however, in general the human family tree has continued its trend toward expanding "bushes" and taxonomic diversity, including the announcement of the new species Australopithecus sediba by Berger and collaborators [7]. The genetic evidence for interbreeding along with the traditional concept of species proposed by Mayr [1] might lead to these Late Pleistocene populations being integrated into a single species; however, it is also clear that a host of phylogenetic and taxonomic problems remains unresolved after subsuming the reproductively viable groups into one species. In addition, since the discovery in September 2003 of Homo floresiensis from Flores Island, different interpretations have raised interesting queries about how much genetic and morphological diversity was present during the Late Pleistocene $[8,9]$. 


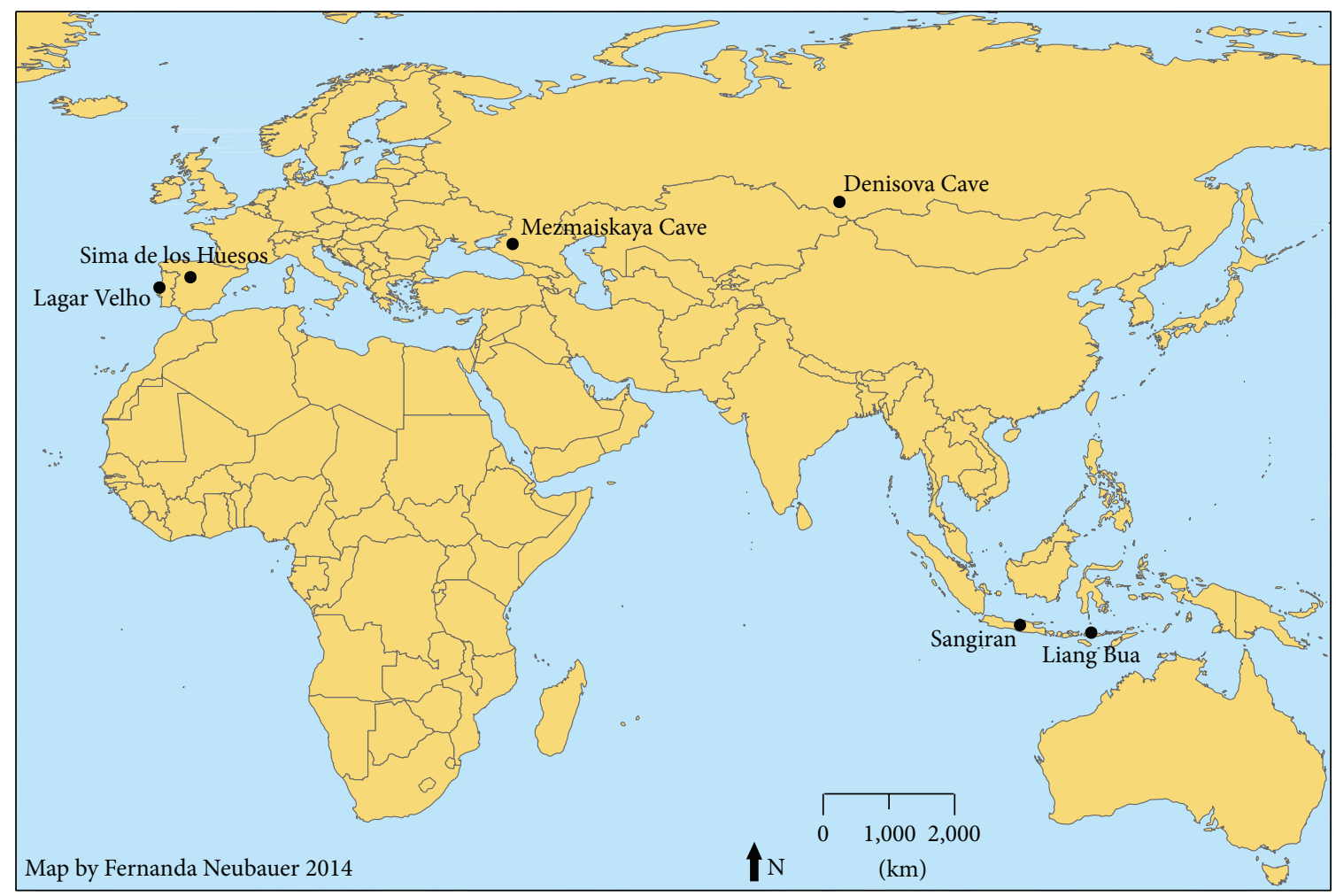

FIGURE 1: Map of the significant site locations discussed in this paper.

In the last ten years, new fossil, archaeological, and genetic data have significantly altered our understanding of the peopling of the Old World in the Late Pleistocene. This paper aims to discuss the nature and implications of the evidence with respect to Homo floresiensis, Neanderthals, and Denisovans. This paper briefly reviews these major Late Pleistocene discoveries in the Old World and their significance to the study of human evolution. It is not my intention to settle any debates, new or old, but instead to discuss briefly how several recent discoveries bring new complexities and considerations to the field of Old World Late Pleistocene research related to Homo floresiensis, Neanderthals, and Denisovans.

\section{Homo floresiensis}

In 2004 Brown, Morwood and collaborators published the findings of skeletal remains of small-bodied hominins from their excavations in Liang Bua (Figure 1), a large limestone cave on the island of Flores in eastern Indonesia, and suggested that they represented a new species that they named Homo floresiensis $[8,9]$. According to the original reports, the hominins on Flores were $1 \mathrm{~m}$ tall and had an endocranial volume of approximately $380 \mathrm{~cm}^{3}$, equivalent to the smallest-known australopithecines. The most complete specimen named LB1 was identified as a female due to its pelvic anatomy, and as an adult because of the teeth eruption and wear and epiphyseal unions. LB1 skeletal bones, some of which were still articulated, included a fairly complete cranium and mandible. The bones were recovered from a small area dated with calibrated accelerator mass spectrometry (AMS) to c. $18 \mathrm{ka}$ by two samples (ANUA-27116 and ANUA-27117). Associated deposits contained 32 stone tools and faunal remains, including Komodo dragon and dwarfed species of Stegodon (MNI 26). But another level that also contains $H$. floresiensis remains had up to 5,500 artifacts per cubic meter, including points, blades, and perforators. LB2, the left mandibular third premolar of another specimen, yielded an age of $37.7 \pm 0.2 \mathrm{ka}$ (sample LB-JR-6A/13-23) by thermal ionization mass spectrometry (TIMS). Based on these dates, the researchers originally suggested that the $H$. floresiensis existed from before $38 \mathrm{ka}$ until at least $18 \mathrm{ka}$. In the following year, after more evidence was analyzed from the site, Morwood et al. [10] inferred new dates of 95-74 to $12 \mathrm{ka}$ for the presence of $H$. floresiensis in Liang Bua. The new discoveries included the butchered Stegodon bones, evidence of the use of fire, and hominin remains of a second adult mandible and postcranial material from other individuals.

As the discoveries received global attention, scholars soon questioned where to place $H$. floresiensis in the hominin phylogenetic tree, and within broader cladistic analysis (e.g., [11-13]). Some scholars hypothesized that $H$. floresiensis evolved from early Javanese Homo erectus with dramatic island dwarfism due to long-term isolation (e.g., [14]). This idea was first proposed by the discoverers [8,9], who soon after reviewed their assessment and concluded that the genealogy of the new hominin species was uncertain due to some of their similarities with Australopithecus, and were not likely descendants of $H$. erectus nor $H$. sapiens 
[10]. Others suggested that $H$. floresiensis were not insular dwarfed descendants of $H$. erectus, but of a lineage of Ling Bua hominins that left Africa before 1.8 Ma, likely before the evolution of the genus Homo, and arrived on Flores in the Middle Pleistocene (e.g., [15]). Contrary to both of these perspectives, there are scholars who have refuted the idea that $H$. floresiensis represent a new species, arguing that the specimens represent a microcephalic Homo sapiens, which is a pathological anomaly (e.g., [16, 17]). However, a growing number of researches have supported the idea that they represent a new and puzzling species (e.g., [8$15,18-25])$. They have critiqued the pathological view due to its inability to explain how a diseased population could persist for over 50,000 years and encompass the full range of phenotypes observed in $\mathrm{H}$. floresiensis. In addition, the Roberts et al. [26] study did not support the claims that the variety of specimens with consistent skeletal morphological features in different levels was explained by taphonomic or disturbance events as described by proponents of the pathological disorder theory. They collected an extensive series of 85 samples that were dated using 7 numericalage methods (radiocarbon, thermoluminescence, optically stimulated luminescence, infrared-stimulated luminescence, uranium-series, electron spin resonance, and electron spin resonance/uranium-series) to establish the geochronological information for Liang Bua and its immediate environments. This produced a robust chronological framework for the archaeological, faunal, and sedimentary sequences at Liang Bua. The results obtained indicated good stratigraphic coherence, and the age estimates provide a series of self-consistent chronologies for the hominin and artifact-bearing deposits spanning the last c. $100 \mathrm{ka}$. There is evidence that hominins were present in Flores as early as 1 Ma by the discovery of 45 stone tools in situ, but no animal or hominin remains were found in that context [27]. There is also evidence of $H$. erectus recovered at Sangiran (Central Java, Indonesia) (Figure 1) dating to nearly $1.6 \mathrm{Ma}$ and of more than 80 specimens from ages ranging from 1.51 to $0.9 \mathrm{Ma}$ [28].

Due to the lack of evidence, however, it is unclear whether $H$. floresiensis descended from these first inhabitants of Flores Island and went through an insular dwarfing process, as well as if they were a completely different species or variants of the same species of Homo. Furthermore, there is still no agreement on whether they belong to the genus Homo or Australopithecus. Only future genetic studies will disclose whether $H$. floresiensis were able to interbreed with other hominins, or if modern humans share a percentage of their DNA as in the case of Neanderthals and Denisovans.

\section{Neanderthals}

The first Neanderthal skeleton recovered was a child's skull excavated in late 1829 or early 1830 , estimated to be four to six years old at the age of death, although the discovery was only recognized about a century later. The specimen was recovered at Engis cave in Belgium by the physician Schmerling [29, page 379] and [30, page 17]. However, the first skeletal remains to be recorded as a Neanderthal were a male found in the Kleine Feldhofer Grotte near Dusseldorf, Germany, in 1856. King [31] soon created a new taxonomic category, Homo neanderthalensis. Today however many scholars attribute Neanderthals to the taxonomic category Homo sapiens neanderthalensis to emphasize that they were more similar to modern Homo sapiens than being different (e.g., [32]). Indeed, after the recent discovery in 2010 by Green et al. [4] in which modern humans share a percentage of the Neanderthal genomic DNA sequence and therefore interbred with $\mathrm{AMH}$, some scholars now accept that they were not two different species but instead represent variants of the same. Their studies indicate that non-African individuals retain an average of 1 to $4 \%$ of Neanderthal DNA. Jankovié [29, page 395], before the announcements of these genetic findings, had already defended this hypothesis and argued that "Neanderthals are seen as an extinct group of populations, not an extinct or separated species, and are expected to have contributed to some extent to the early modern human gene pool in Europe." In addition, Zilhão and collaborators [33-35] had also argued that Neanderthals interbreed with AMH much earlier than the genetic findings. The authors argued that the fossil remains of a child recovered from the Lagar Velho rock shelter in Portugal (Figure 1) combined skeletal features of Neanderthal (e.g., short, thick limb bones) and modern humans (e.g., modern teeth and chin), representing to them direct evidence that both interbred and contributed to our gene pool. The authors suggested that Neanderthals disappeared by being absorbed into the early modern human population. Radiocarbon results from the charcoal lens under the child's legs and from animal bones associated with the burial yielded a date of $24.5 \mathrm{ka}$, about 3,000 years after Neanderthals presumably disappeared from western Iberia.

To date, the skeletal remains of more than 500 Neanderthal individuals are known, and surprisingly about half of these are children [30, page 17]. This represents a high number of child specimens if we consider that hominin remains are rare because the fossilization and survival of a skeletal over a large time span is an unusual and lucky event. Due to their smaller size and fragility, the finding of subadult skeletal remains is even rarer. This factor led Stapert [30, page 17] to suggest that Neanderthal child mortality must have been higher than $50 \%$ and they often died quite young. The author also argues that there may have been many reasons for the high mortality among Neanderthals such as food shortage, unbalanced diet, and violence. However, Estabrook [36] analyzed many Neanderthal skeletal remains to verify if the occurrences of trauma present in them are high. The author [page 346] "found no evidence that Neanderthals experienced trauma more frequently or with a different distribution throughout the body beyond what is commonly experienced by modern humans in the context of hunter-gatherers, nomads, semisedentary foragers, and medieval small landowners." Furthermore, Estabrook' data did not support the assertion that trauma played a more influential role in the lives of Neanderthals than any of the groups mentioned above.

Researchers have also focused on understanding Neanderthal's cognitive capabilities and how their behaviors were 
compared to modern humans. Some scholars have argued that Neanderthals had a shorter childhood compared to AMH (e.g., [37, 38]), while others argued that both had similar growth rates (e.g., [39]). Based on their data of enamel and dental growth studies, Rozzi and de Castro [38] suggest that Neanderthal dental crown formed $15 \%$ quicker than modern humans. If all aspects of dental development were foreshortened to the same degree, it would have taken about 15 years for Neanderthals to reach adulthood. Furthermore they conclude that, despite having a large brain (with cranial capacities of 1,200 to $1,626 \mathrm{~cm}^{3}$ ), Neanderthals were characterized by having a short period of development even compared to their ancestor Homo heidelbergensis. De León et al. [39], however, based on their analysis of Neanderthal neonate brain sizes, argue that the duration of pregnancy of Neanderthals and modern Homo sapiens were similar, suggesting relatively equivalent fetal growth rates. The authors also suggest that Neanderthal brains expanded at a higher rate and attained larger adult volumes than modern Homo sapiens, but they reached adult sizes within the same time period and along equivalent trajectories. Meanwhile, Kondo et al. [40] studied the growth patterns of neurocranium, faces, and mandibles from Neanderthals and modern humans. Their results were interpreted as showing that neurocranial and facial growth were similar in Neanderthals and modern humans but in contrast, the growth of Neanderthal mandibles was more accelerated-at least during the postnatal-to-preadolescent period between ages two and ten years-than that of modern humans. However, the authors conclude that their results are premature and that it is unclear if Neanderthal growth was more accelerated than modern humans or if they represent the same pattern of widely differing growth profiles as modern populations. The studies conducted by Rozzi and de Castro [38], de León et al. [39], and Kondo et al. [40] demonstrate that the question of the length of Neanderthal childhood is a discussion that is still unresolved among scientists.

Although some researchers suggested that Neanderthals did not intentionally bury their dead (e.g., [41]), examining the literature, Pettitt [42, page 3] suggests that there are 32 to 36 convincing indicators of Neanderthal burial practices. Mezmaiskaya Cave (Figure 1), located in northern Caucasus, is an interesting site due to the finding of two intentional burials of Neanderthal infant skeletons that were recovered from layers associated with animal remains and Mousterian artifacts. According to Golovanova et al. [43], the excavations at the site were well executed to the extent that Neanderthal subsistence strategies could be established. The stratigraphic layers containing the burials were radiocarbon dated to $32 \mathrm{ka}$ (LE-4735) and to $>45 \mathrm{ka}$ (LE-3841). The region where the cave site is located is characterized by a rich diversity of fauna and flora. Many thousands of faunal remains were recovered from the Neanderthal Mousterian occupation layers at the site. Medium to large sized mammals were common, with a predominance of steppe bison (Bison priscus), Caucasian goat (Capra caucasica), and Asiatic mouflon (Ovis orientalis). The analysis of a sample of 479 large mammal bones indicated that many exhibit traces of carnivore damage and lithic tool cut marks. Stone tool cut marks were present on $7 \%$ of the bison bones and 5\% of the goat, sheep, and red deer bones, representing different stages of the butchering process, including dismemberment and filleting. The dental crown of the lower third molars was measured to provide the age of mortality of bison (N. 19) and goats and sheep (N. 22), which represent a preference for prime-age adults. This finding led Golovanova et al. [43, page 85] to conclude that "such a profile is not consistent with the pattern of scavenged remains, and these data, in conjunction with the tool cut marks, indicate that most of bison, goat, and sheep remains represent animals hunted by the inhabitants of Mezmaiskaya Cave." Of course the type of meat and edible plants that were part of Neanderthals' diet varied widely from each region depending upon the surrounding fauna and flora available, but the case study from Mezmaiskaya cave shows strong evidence that Neanderthals were efficient hunters. A number of studies have focused on Neanderthal subsistence behavior, most of which portray it as synonymous with hunting and fishing specialization (e.g., [43-45]).

Further, the Paixão-Côrtes et al. [46] study of 162 cognitive genes among Denisovans, H. sapiens, and Neanderthals revealed that, due to the great similarity in some of the cognitive genes, they might have shared more behavioral traits with modern humans than previously thought. AbiRached et al. [47] suggest that on migrating out of Africa, $\mathrm{AMH}$ encountered archaic hominins, residents of Eurasia for more than 200,000 years, who had immune systems that were better adapted to local pathogens, and their interactions significantly shaped AMH immune systems through adaptive introgression of the archaic alleles.

\section{Denisovans}

In 2010, Krause and collaborators [48] reported the discovery of a distal phalanx bone of a young female from the Denisova Cave in Siberia (Figure 1), which was dated by poorly associated fauna to 30 to $50 \mathrm{ka}$. They extracted DNA from the bone and concluded that it belonged to a previously unknown type of archaic hominin. They were cautious to avoid defining the hominins as a new species and instead called them Denisovans. In contrast to every other hominin population (e.g., Neanderthals, H. floresiensis), who have been recognized based on their skeletal morphology, the Denisovans were the first hominin groups identified through genetic evidence. Denisovans were a sister group of Neanderthals that diverged before Neanderthals interbred with $\mathrm{AMH}$. Later there was admixture between Denisovans and the ancestors of Melanesians, involving primarily Denisovan males [49, page 224].

Reich et al. [5, 6] estimated that modern Melanesians have the highest percent of Denisovan DNA, ranging from 4 to $6 \%$. Their genetic studies also indicated that mainland Eurasian populations did not have significant percentages of Denisovan DNA. The ancestors of present-day East Asians were not in Southeast Asia when the Denisova gene flow occurred into the common ancestors of Melanesians. Scholars have invested efforts to understand how they reached Australia and crossed 
the Wallace's Line, one of the world's greatest biogeographic barriers, an achievement previously accomplished by $H$. floresiensis [50]. Genetic studies by Rasmussen et al. [51] indicate a two wave settlement of Asia, which reinforces the hypothesis suggested by Petraglia et al. [52] about an Asian origin of the Denisovans. Native Australians are descendants of an early human dispersal into eastern Asia that occurred probably 62 to $75 \mathrm{ka}$. The findings of stone tools dated to c. $74 \mathrm{ka}$ in Jwalapuram in Southern India strengthen this hypothesis [53]. The second dispersal gave rise to modern Asians 25 to $38 \mathrm{ka}$.

Adding to this puzzle is the fact that Denisovan DNA was identified in hominins recovered from Sima de los Huesos in Spain (Figure 1) [54], a site that has provided long-term record of ancient DNA, including DNA from the remains of a Middle Pleistocene cave bear [55]. The Sima de los Huesos skeletal remains show Neanderthal-derived features (e.g., dental, mandibular, midfacial, supraorbital, and occipital morphology), but their mtDNA shares a common ancestor with Denisovans rather than Neanderthals [54]. Prüfer et al. [56] based on their genomic studies suggest that several gene flow events occurred among Neanderthals, Denisovans, and $\mathrm{AMH}$, possibly including gene flow into Denisovans from an unknown archaic group (perhaps $H$. erectus). Their analysis indicates that interbreeding occurred among many hominin populations in the Late Pleistocene, but the extent of gene flow between them was generally low.

\section{Discussion}

Three major theories have been hypothesized to explain the human evolutionary trajectories observed during the Late Pleistocene, and these models are popularly titled: Out of Africa, Multiregional, and Assimilation. In the Out of Africa or Recent African Origin model, H. sapiens evolved in Africa and migrated to Eurasia and Australia after $50 \mathrm{ka}$ and rapidly replaced the other Homo species, such as Neanderthals [57-59]. Neanderthals are seen as a different species than $\mathrm{AMH}$, and the two did not interbreed. Utilizing a branching/replacement model for human evolution, in this model $H$. erectus is placedas the ancestor to modern $H$. sapiens. The Out of Africa model, however, is too rigid to keep up with the new evidences from archaeological data and genetics. Adding to this complexity, researchers must now consider how new data informs on scenarios of previous hominin dispersions (e.g., [60]).

Under the multiregional hypothesis, human populations living in Africa and Eurasia have been genetically connected since the time of $H$. erectus. Because of this gene flow, they have evolved together as a single evolutionary lineage. The concept of multiregional does not mean independent multiple origins, but rather a dependence on genetic exchanges to explain how differentiation, geographic variation, and evolutionary changes within the human species took place [61, page 134]. A middle road approach attempts to merge parts of both of these theories, known as the Assimilation model. In this model, early AMH after migrating from Africa interbred with the initial populations that they encountered in Eurasia, which were still archaic. In this way, archaic genes entered the pool and passed their traits back to $\mathrm{AMH}$, which quickly completely replaced them [62]. The key strengths of both the Multiregional and Assimilation models are in their ability to account for recent genetic and archaeological evidences and are both plausible to explain human evolution during the Late Pleistocene.

To conclude, in the last ten years scholars have introduced a variety of new hominin species, along with variants of a singular species. Many are potential candidates for the ancestor of our genus, but only time will disclose whether they will continue to be recognized as unique variants [63, page 215]. It is now acknowledged that Neanderthals and Denisovans probably did not go extinct in the classical sense but instead were merged with other populations, and some of their genetic heritage is still retained in the present-day human populations [61, page 132]. While a Neanderthal genetic contribution to the present-day gene pool is evidenced in all human populations outside Africa, a contribution from Denisovans is found exclusively in island Southeast Asia and Oceania $[4-6,54]$. With all of the evidence for interbreeding, it is most likely that the hominin phylogeny represents expansive networks instead of the traditional phylogenetic trees and bushes. Furthermore, as suggested by de Castro and Martinón-Torres [60, page 108], "[t]rying to classify the hominid populations into a 'species' scheme too rigidly, and the understanding of dispersals events as directional and lineal migrations instead of expansion/contraction hominid pulses, undoubtedly interfere in the understanding of the evolutionary scenario of the genus Homo during the Pleistocene." In future studies, it will be necessary to integrate several lines of evidence-genetic, archaeological, and fossil-in order to unravel the story of our own species.

\section{Conflict of Interests}

The author declares that there is no conflict of interests regarding the publication of this paper.

\section{Acknowledgments}

The author thank Michael J. Schaefer for editing the drafts of this paper and making comments and Nam C. Kim for his guidance during the production of this paper. She also thanks CAPES Foundation (Coordenação de Aperfeiçoamento de Pessoal de Nível Superior) for financial support. Finally, she would like to thank the editor Santos Alonso, Marina Martínez de Pinillos González, and the two other anonymous reviewers for their invaluable comments and suggestions.

\section{References}

[1] E. Mayr, Systematics and the Origin of Species from the Viewpoint of a Zoologist, Columbia University Press, New York, NY, USA, 1942.

[2] R. L. Mayden, "A hierarchy of species concepts: the denouement in the saga of the species problem," in Species: The Units of Biodiversity, M. F. Claridge, H. A. Dawah, and M. R. Wilson, Eds., pp. 381-424, Chapman \& Hall, London, UK, 1997. 
[3] K. De Queiroz, "Ernst Mayr and the modern concept of species," Proceedings of the National Academy of Sciences of the United States of America, vol. 102, no. 1, pp. 6600-6607, 2005.

[4] R. E. Green, J. Krause, A. W. Briggs et al., "A draft sequence of the Neandertal genome," Science, vol. 328, pp. 710-722, 2010.

[5] D. Reich, R. E. Green, M. Kircher et al., "Genetic history of an archaic hominin group from Denisova cave in Siberia," Nature, vol. 468, no. 7327, pp. 1053-1060, 2010.

[6] D. Reich, N. Patterson, M. Kircher et al., "Denisova admixture and the first modern human dispersals into Southeast Asia and Oceania," The American Journal of Human Genetics, vol. 89, no. 4, pp. 516-528, 2011.

[7] L. R. Berger, D. J. de Ruiter, S. E. Churchill et al., "Australopithecus sediba: a new species of homo-like australopith from South Africa," Science, vol. 328, no. 5975, pp. 195-204, 2010.

[8] P. Brown, T. Sutikna, M. J. Morwood, R. P. Soejono, E. W. Saptomo, and R. A. Due, "A new small-bodied hominin from the Late Pleistocene of Flores, Indonesia," Nature, vol. 431, no. 7012, pp. 1055-1061, 2004.

[9] M. J. Morwood, R. P. Soejono, R. G. Roberts et al., "Archaeology and age of a new hominin from Flores in Eastern Indonesia," Nature, vol. 431, no. 7012, pp. 1087-1091, 2004.

[10] M. J. Morwood, P. Brown, T. Sutikna et al., "Further evidence for small-bodied hominins from the Late Pleistocene of Flores, Indonesia," Nature, vol. 437, no. 7061, pp. 1012-1017, 2005.

[11] D. Argue, M. J. Morwood, T. Sutikna, and E. W. Saptomo, "Homo floresiensis: a cladistic analysis," Journal of Human Evolution, vol. 57, no. 5, pp. 623-639, 2009.

[12] D. Argue, M. Morwood, T. Sutikna, and E. W. Saptomo, "A Reply to Trueman's "A new cladistic analysis of Homo floresiensis," Journal of Human Evolution, vol. 59, no. 2, pp. 227-230, 2010.

[13] J. W. H. Trueman, "A new cladistic analysis of Homo floresiensis," Journal of Human Evolution, vol. 59, no. 2, pp. 223-226, 2010.

[14] Y. Kaifu, "Craniofacial morphology of Homo floresiensis: description, taxonomic affinities, and evolutionary implication," Journal of Human Evolution, vol. 61, pp. 644-682, 2011.

[15] P. Brown and T. Maeda, "Liang Bua Homo floresiensis mandibles and mandibular teeth: a contribution to the comparative morphology of a new hominin species," Journal of Human Evolution, vol. 57, no. 5, pp. 571-596, 2009.

[16] R. D. Martin, A. M. MacLarnon, J. L. Phillips, and W. B. Dobyns, "Flores hominid: new species or microcephalic dwarf?" Anatomical Record A: Discoveries in Molecular, Cellular, and Evolutionary Biology, vol. 288, no. 11, pp. 1123-1145, 2006.

[17] R. C. Vannucci, T. F. Barron, and R. L. Holloway, "Craniometric ratios of microcephaly and LB1, Homo floresiensis, using MRI and endocasts," Proceedings of the National Academy of Sciences of the United States of America, vol. 108, no. 34, pp. 14043-14048, 2011.

[18] D. Argue, D. Donlon, C. Groves, and R. Wright, "Homo floresiensis: microcephalic, pygmoid, Australopithecus, or Homo?" Journal of Human Evolution, vol. 51, no. 4, pp. 360-374, 2006.

[19] P. Brown, "LB1 and LB6 Homo floresiensis are not modern human (Homo sapiens) cretins," Journal of Human Evolution, vol. 62, no. 2, pp. 201-224, 2012.

[20] S. G. Larson, W. L. Jungers, M. J. Morwood et al., "Homo floresiensis and the evolution of the hominin shoulder," Journal of Human Evolution, vol. 53, no. 6, pp. 718-731, 2007.

[21] S. G. Larson, W. L. Jungers, M. W. Tocheri et al., "Descriptions of the upper limb skeleton of Homo floresiensis," Journal of Human Evolution, vol. 57, no. 5, pp. 555-570, 2009.
[22] S. H. Montgomery, "Primate brains, the "island rule" and the evolution of Homo floresiensis," Journal of Human Evolution, vol. 65, no. 6, pp. 750-760, 2013.

[23] M. J. Morwood, T. Sutikna, E. W. Saptomo, D. R. Hobbs, and K. E. Westaway, "Preface: research at Liang Bua, Flores, Indonesia," Journal of Human Evolution, vol. 57, no. 5, pp. 437-449, 2009.

[24] C. M. Orr, M. W. Tocheri, S. E. Burnett et al., "New wrist bones of Homo floresiensis from Liang Bua (Flores, Indonesia)," Journal of Human Evolution, vol. 64, no. 2, pp. 109-129, 2013.

[25] E. M. Weston and A. M. Lister, "Insular dwarfism in hippos and a model for brain size reduction in Homo floresiensis," Nature, vol. 459, no. 7243, pp. 85-88, 2009.

[26] R. G. Roberts, K. E. Westaway, J.-X. Zhao et al., "Geochronology of cave deposits at Liang Bua and of adjacent river terraces in the Wae Racang valley, Western Flores, Indonesia: a synthesis of age estimates for the type locality of Homo floresiensis," Journal of Human Evolution, vol. 57, no. 5, pp. 484-502, 2009.

[27] A. Brumm, G. M. Jensen, G. D. van den Bergh et al., "Hominins on Flores, Indonesia, by one million years ago," Nature, vol. 464, no. 7289, pp. 748-752, 2010.

[28] Y. Zaim, R. L. Ciochon, J. M. Polanski et al., "New 1.5 millionyear-old Homo erectus maxilla from Sangiran (Central Java, Indonesia)," Journal of Human Evolution, vol. 61, no. 4, pp. 363$376,2011$.

[29] I. Jankovié, "Neandertals...150 years later," Collegium Antropologicum, vol. 28, supplement 2, no. 2, pp. 379-401, 2004.

[30] D. Stapert, "Neanderthal children and their flints," PalArch Journal of Archaeology of Northwest Europe, vol. 1-2, pp. 16-39, 2007.

[31] W. King, "The reputed fossil man of neanderthal," Quarterly Journal of Science, vol. 1, pp. 88-97, 1864.

[32] C. P. T. Baillie, "Neandertals: unique from humans, or uniquely human?" Kroeber Anthropological Society, vol. 103, no. 1, pp. 93107, 2013.

[33] C. Duarte, J. Maurício, P. B. Pettitt et al., "The early Upper Paleolithic human skeleton from the Abrigo do Lagar Velho (Portugal) and modern human emergence in Iberia," Proceedings of the National Academy of Sciences of the United States of America, vol. 96, no. 13, pp. 7604-7609, 1999.

[34] J. Zilhão, "Fate of the Neandertals," Archaeology, vol. 53, no. 4, pp. 24-29, 2000.

[35] J. Zilhão and E. Trinkaus, Eds., Portrait of the Artist as a Child: The Gravettian Human Skeleton from the Abrigo do Lagar Velho and Its Archeological Context, Trabalhos de Arqueologia 22, Instituto Português de Arqueologia, Lisboa, Portugal, 2002.

[36] V. H. Estabrook, Sampling biases and new ways of addressing the significance of trauma in Neandertals [Ph.D. dissertation], The University of Michigan, Ann Arbor, Mich, USA, 2009.

[37] J. Hawcroft and R. Dennell, "Neanderthal cognitive life history and its implications for material culture," in Children and Material Culture, J. S. Derevenski, Ed., pp. 89-99, Routledge, London, UK, 2000.

[38] F. V. R. Rozzi and J. M. B. de Castro, "Surpisingly rapid growth in Neanderthals," Nature, vol. 428, no. 6986, pp. 936-939, 2004.

[39] M. S. P. de León, L. Golovanova, V. Doronichev et al., "Neanderthal brain size at birth provides insights into the evolution of human life history," Proceedings of the National Academy of Sciences of the United States of America, vol. 105, no. 37, pp. 13764-13768, 2008.

[40] O. Kondo, H. Ishida, T. Hanihara, T. Wakebe, Y. Dodo, and T. Akazawa, "Cranial ontogeny in Neandertal children: evidence 
from neurocranium, face and mandible," in Current Trends in Dental Morphology Research, E. Zadzinska, Ed., pp. 243-255, University of Lodz Press, Lodz, Poland, 2005.

[41] R. H. Gargett, "Grave shortcomings: the evidence for Neandertal burial," Current Anthropology, vol. 30, no. 2, pp. 157-190, 1989.

[42] P. B. Pettitt, "The Neanderthal dead: exploring mortuary variability in middle paleolithic eurasia," Before Farming, vol. 1, no. 4, pp. 1-19, 2002.

[43] L. V. Golovanova, J. F. Hoffecker, V. M. Kharitov, and G. P. Romanova, "Mezmaiskaya cave: a Neanderthal occupation in the Northern Caucasus," Current Anthropology, vol. 40, no. 1, pp. 77-86, 1999.

[44] R. Davies and S. Underdown, "The Neanderthals: a social synthesis," Cambridge Archaeological Journal, vol. 16, no. 2, pp. 145-164, 2006.

[45] B. L. Hardy and M.-H. Moncel, "Neanderthal use of fish, mammals, birds, starchy plants and wood 125-250,000 years ago," PLoS ONE, vol. 6, no. 8, Article ID e23768, 2011.

[46] V. R. Paixão-Côrtes, L. H. Viscardi, F. M. Salzano, M. Cátira bortolini, and T. Hünemeier, "The cognitive ability of extinct hominins: bringing down the hierarchy using genomic evidences," American Journal of Human Biology, vol. 25, no. 5, pp. 702-705, 2013.

[47] L. Abi-Rached, M. J. Jobin, S. Kulkarni et al., "The shaping of modern human immune systems by multiregional admixture with archaic humans," Science, vol. 334, no. 6052, pp. 89-94, 2011.

[48] J. Krause, Q. Fu, J. M. Good et al., "The complete mitochondrial DNA genome of an unknown hominin from southern Siberia," Nature, vol. 464, no. 7290, pp. 894-897, 2010.

[49] M. Meyer, M. Kircher, M.-T. Gansauge et al., "A high-coverage genome sequence from an archaic Denisovan individual," Science, vol. 338, no. 6104, pp. 222-226, 2012.

[50] A. Cooper and C. B. Stringer, "Did the denisovans cross Wallace's line?” Science, vol. 342, pp. 321-323, 2013.

[51] M. Rasmussen, X. Guo, Y. Wang et al., "An aboriginal Australian genome reveals separate human dispersals into Asia," Science, vol. 334, no. 6052, pp. 94-98, 2011.

[52] M. Petraglia, R. Korisettar, N. Boivin et al., "Middle Paleolithic assemblages from the Indian subcontinent before and after the Toba super-eruption," Science, vol. 317, no. 5834, pp. 114-116, 2007.

[53] M. Martinon-Torres, R. Dennell, and J. M. Bermudez de Castro, "The Denisova hominin need not be an out of Africa story," Journal of Human Evolution, vol. 60, no. 2, pp. 251-255, 2011.

[54] M. Meyer, Q. Fu, A. Aximu-Petri et al., "A mitochondrial genome sequence of a hominin from Sima de los Huesos," Nature, vol. 505, pp. 403-406, 2014.

[55] J. Dabney, M. Knapp, I. Glocke et al., "Complete mitochondrial genome sequence of a Middle Pleistocene cave bear reconstructed from ultrashort DNA fragments," Proceedings of the National Academy of Sciences of the United States of America, 2013.

[56] K. Prüfer, F. Racimo, N. Patterson et al., "The complete genome sequence of a Neanderthal from the Altai mountains," Nature, vol. 505, no. 7481, pp. 43-49, 2014.

[57] R. G. Klein, "Anatomy, behavior, and modern human origins," Journal of World Prehistory, vol. 9, no. 2, pp. 167-198, 1995.

[58] R. G. Klein, "Out of Africa and the evolution of human behavior," Evolutionary Anthropology, vol. 17, no. 6, pp. 267-281, 2008.
[59] R. G. Klein, The Human Career: Human Biological and Cultural Origins, The University of Chicago Press, Chicago, Ill, USA, 3rd edition, 2009.

[60] J. M. B. de Castro and M. Martinón-Torres, "A new model for the evolution of the human Pleistocene populations of Europe," Quaternary International, vol. 295, pp. 102-112, 2013.

[61] M. H. Wolpoff, J. Hawks, and R. Caspari, "Multiregional, not multiple origins," American Journal of Physical Anthropology, vol. 112, pp. 129-136, 2000.

[62] F. H. Smith, I. Janković, and I. Karavanić, "The assimilation model, modern human origins in Europe, and the extinction of Neandertals," Quaternary International, vol. 137, no. 1, pp. 7-19, 2005.

[63] L. Cowgill, "One year in biological anthropology: species, integration, and boundaries in 2010," American Anthropologist, vol. 113, no. 2, pp. 213-221, 2011. 

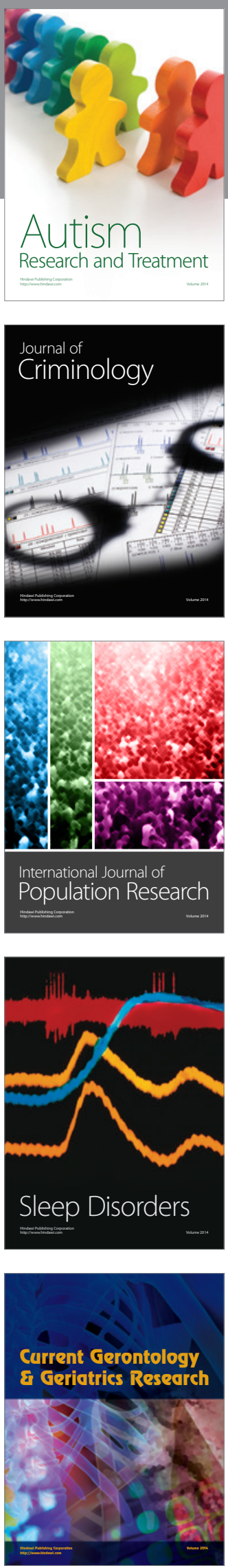
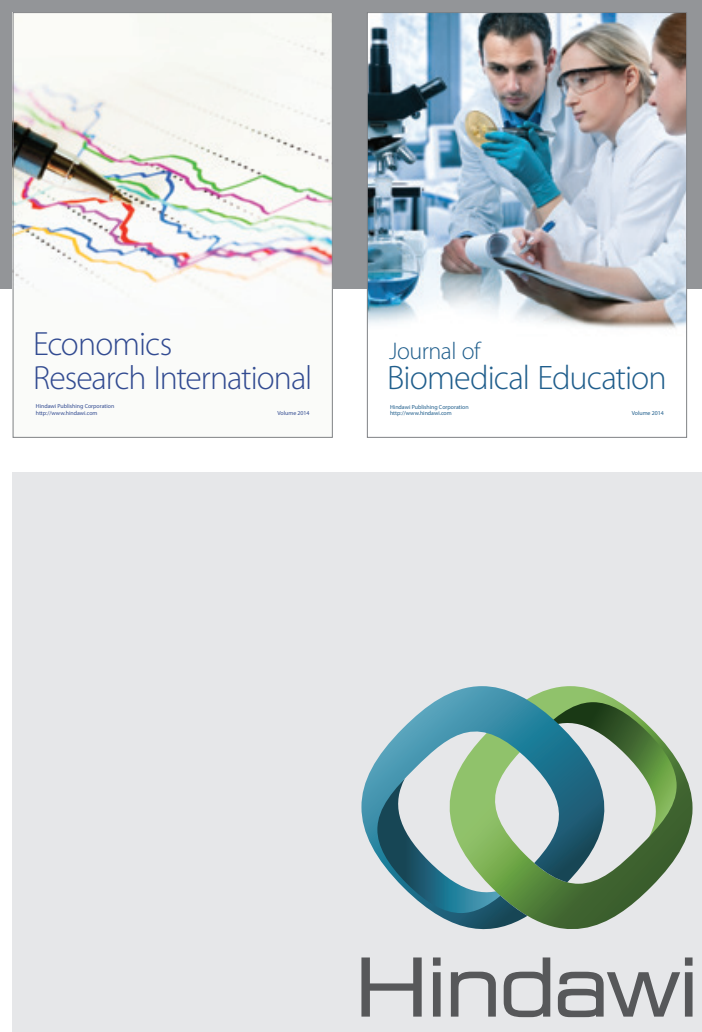

Submit your manuscripts at

http://www.hindawi.com
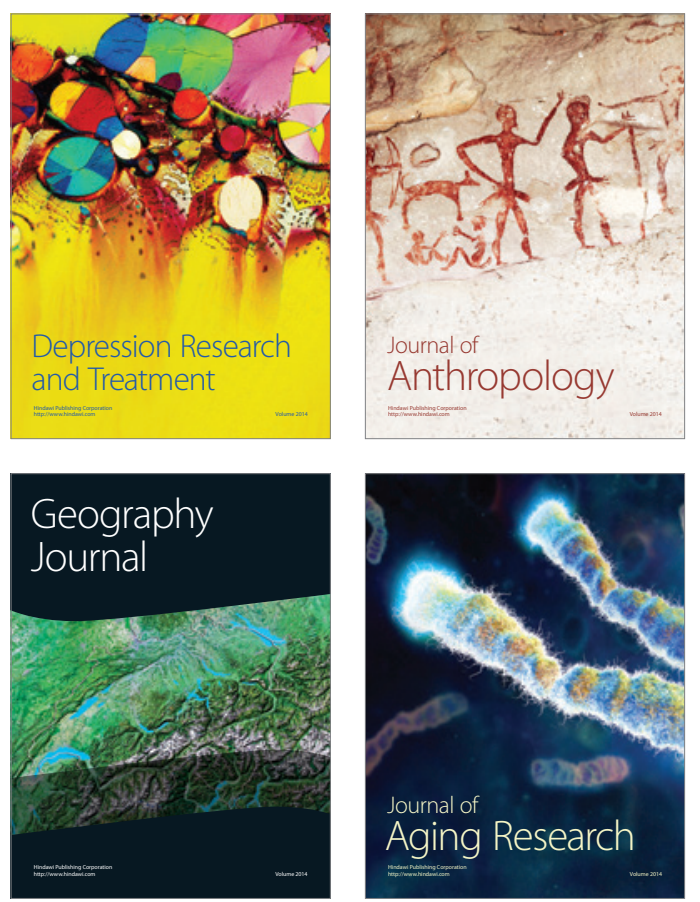
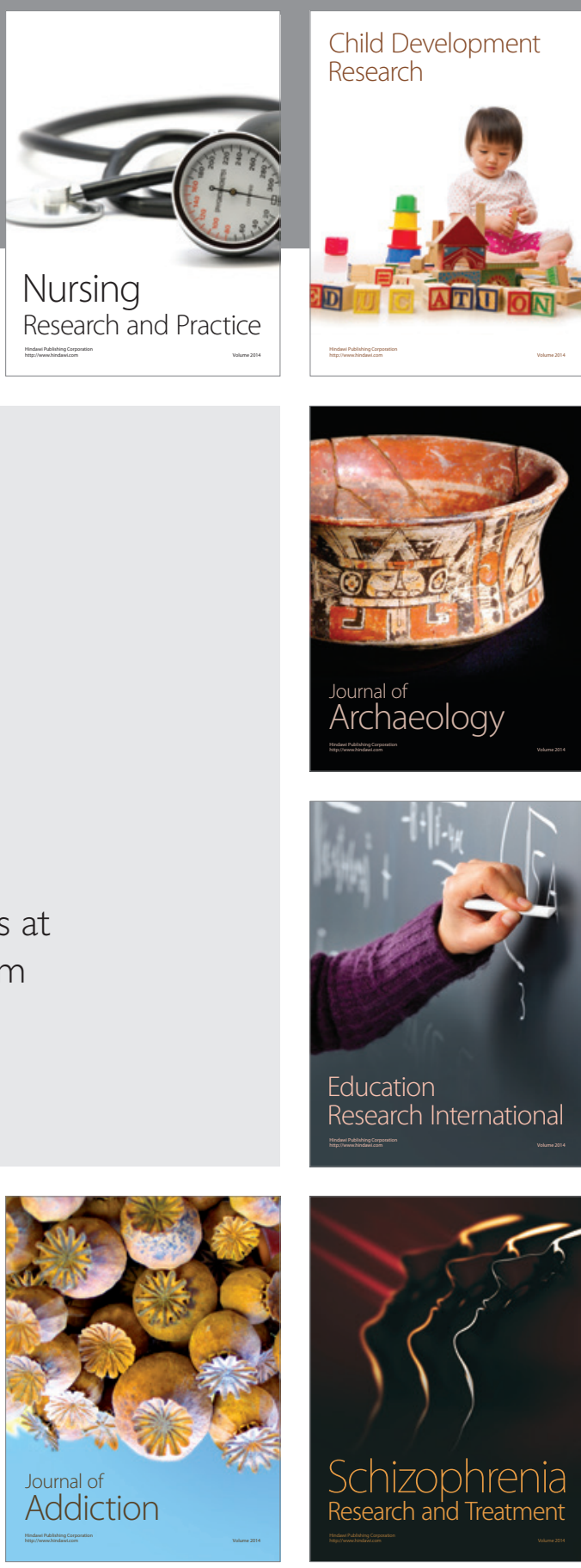

(D)
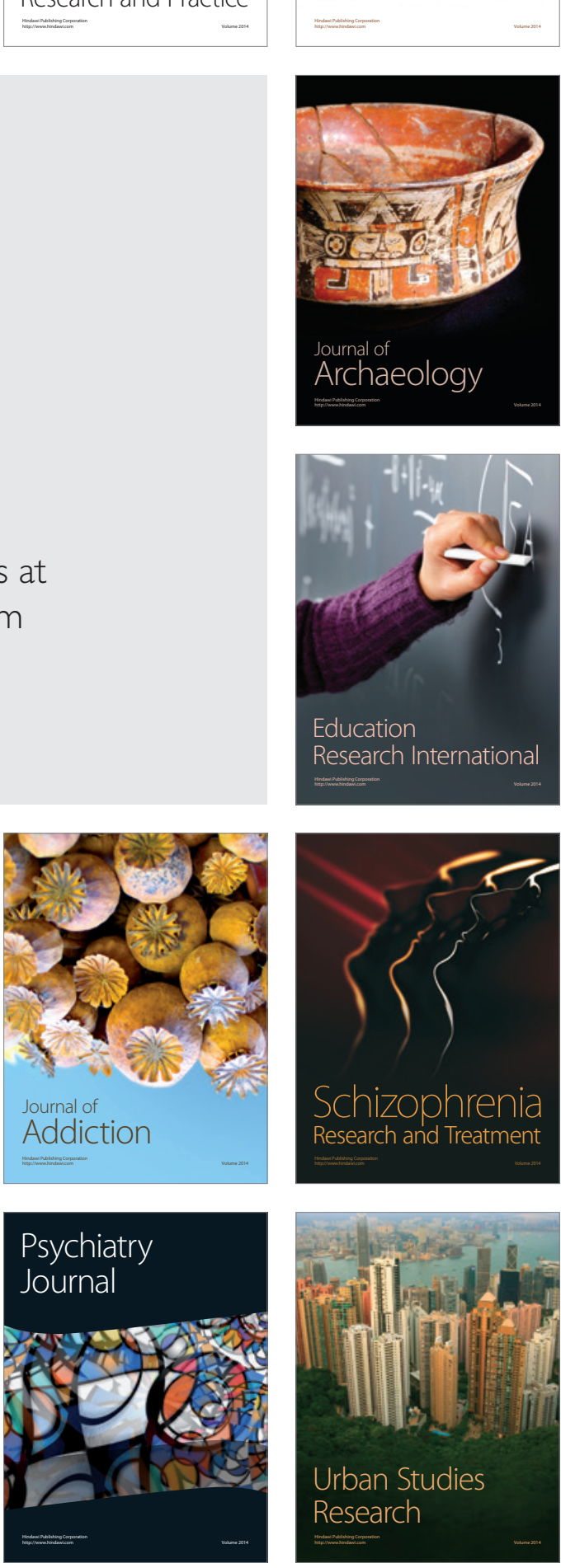